\title{
Investigation into public anxiety symptoms and preventive measures during the COVID-19 outbreak in Taiwan
}

\section{Li Ping Wong ( $\sim$ wonglp@ummc.edu.my )}

University of Malaya https://orcid.org/0000-0002-0107-0532

\section{Chia-Chun Hung}

National Yang Ming University

Haridah Alias

University of Malaya

Tony Szu-Hsien Lee

National Taiwan Normal University

\section{Research Article}

Keywords: COVID-19, STAI-6, preventive measures, public anxiety, Taiwan

Posted Date: April 20th, 2020

DOI: https://doi.org/10.21203/rs.3.rs-23432/v1

License: (c) (i) This work is licensed under a Creative Commons Attribution 4.0 International License. Read Full License 


\section{Abstract}

Background: The objective of this study was to investigate anxiety symptoms and preventive measures being taken against COVID-19. The study also aimed to compare the association between preventive measures and anxiety symptoms during the week immediately preceding the study and those symptoms and measures at the beginning of the outbreak.

Methods: A cross-sectional population survey using an online questionnaire commenced on 14 February 2020. The study participants were residents of Taiwan and were aged between 20 and 70 years. The 6item state version of the State-Trait Anxiety Inventory (STAI-6) was used to assess anxiety symptoms. The questions about preventive measures asked participants about their personal protection, cough etiquette, contact precautions, voluntary quarantine, and prompt reporting.

Results: Of a total of 3,555 completed responses, a total of 52.1\% (95\% Confidence Interval [CI] 50.453.7) of the respondents reported having moderate to severe levels of anxiety symptoms in the past week, whereas $48.8 \%(95 \% \mathrm{Cl} 47.2-50.5)$ reported that they had had moderate to severe levels of anxiety symptoms at the beginning of the outbreak. The median scores for anxiety symptoms in the past week and at the beginning of the outbreak were 46.7 (IQR [Interquartile Range] 36.7-53.3) and 43.3 (IQR 36.753.3), respectively. The median scores for the preventive measures taken in the past week and at the beginning of the outbreak were 26.0 (IQR 21.0-30.0) and 24.0 (IQR 19.0-28.0), respectively, out of a maximum score of 36 . In the multivariate analysis, having an increased anxiety symptom score from the beginning of the outbreak to the past week (adjusted $\mathrm{OR}=7.38,95 \% \mathrm{Cl} 6.28-8.66$ ) was a strongly significant determinant of having an increased preventive measures score in the past week compared with score at the beginning of the outbreak.

Conclusions: The study reveals the need to reduce levels of public anxiety and to maintain appropriate levels of infection prevention against COVID-19. The psychological effects and psychobehavioural responses to the outbreak found in this study provide important information about developing and implementing effective preventive and emotional regulation control strategies.

\section{Background}

On 9 January 2020, a novel coronavirus was detected as the causative agent linked to cases of pneumonia reported in Wuhan, and the genome sequence was made public [1]. Subsequently, the rapid spread of the outbreak across Wuhan and, at a later date, outside mainland China prompted the Chinese government to take immediate action to carry out a lockdown of the epicentre and several nearby cities in the province of Hubei. The rapid spread of the novel coronavirus has caused much anxiety and stigma and, on 11 February 2020 the World Health Organization (WHO) declared that the official name for the new coronavirus disease was COVID-19 [2]. 
The severity and highly contagious nature of COVID-19 has sparked concern worldwide and especially in the countries neighbouring China. The close proximity of Taiwan to China, coupled with the high frequency of cross-border travel, has placed Taiwan as one of the most highly threatened countries, among the other neighbouring countries in Asia, in relation to a COVID-19 outbreak. The Taiwanese government has raised the levels of alert and worry about a potential COVID-19 outbreak in the country. The country has also issued an advisory warning against travel to China. At a later date, various measures were undertaken by the Taiwan government to contain the spread of the COVID-19 virus, including travel bans, and quarantine for those who have recently been to China and who have had close contact with confirmed cases of COVID-19. Despites these measures, the first case of COVID-19 in Taiwan was reported on 21 January 2020. On 8 February, the number of confirmed cases in Taiwan had increased to 18. On 16 February, the first coronavirus death was reported in Taiwan, and the total number of confirmed cases was 20. The first death, from a locally transmitted case in Taiwan, also marked the fifth fatality outside mainland China [3]. Taiwan has been listed by the Centers for Disease Control and Prevention as one of the countries with an apparent community spread [4].

The COVID-19 outbreak threatens not only the life of those infected but also the psychological health of the affected community [5]. The lessons learned from previous outbreaks such as Ebola, severe acute respiratory syndrome (SARS) and the 2009 influenza A (H1N1) have led to worldwide recognition of the importance of addressing morbidities related to mental health associated with the outbreak [6-9]. The impact of such morbidities during a disease outbreak is crucial, not only because it results in a significant weakening in social and other areas of functioning, including an impairment in preventive measures $[10,11]$, but also because excessive mental distress may have a number of biological effects, including reduced cell-mediated immunity and increased inflammatory processes [12,13]. As the preliminary evidence suggests that older adults, and people with underlying health conditions or compromised immune systems, might be at higher risk of mortality with COVID-19 [14], it is important for the general population to reduce the distress associated with the outbreak in order to maintain a strong immune system and thus reduce the risk of infection.

Considering the strong psychological effect of the COVID-19 outbreak, it is tremendously important to assess the lay public's psychobehavioural response to the outbreak in order to develop and implement effective preventive and emotional regulation control strategies. An important element of outbreak management is the appropriate psychobehavioural response to preventive measures to minimize the spread of infection. Experiences from the previous SARS epidemic underline the importance of appropriate behavioural responses in controlling an epidemic $[15,16]$.

Because of the importance of determining the level of psychological distress and understanding the psychobehavioural consequences of COVID-19 among the general public while the epidemic is still ongoing, the objective of this study is to investigate the anxiety symptoms among the general public caused by COVID-19, and assess the measures they are taking against COVID-19. In particular, this study aims to compare the anxiety symptoms and preventive measures during the week immediately prior to 
the study, while the outbreak was still on the rise, and at the time the COVID-19 outbreak as first reported in China.

\section{Methods}

\section{Study design and participants}

We commenced a cross-sectional, web-based anonymous survey using an online questionnaire on 14 February 2020. The inclusion criteria were that the respondents were Taiwan residents who were between 20 and 70 years old. Participants were informed that their participation was voluntary, and consent was implied on completion of the questionnaire. In this online survey, consent obtained from the participants was verbal and the Institutional Review Board has waived written (signed) consent. Our survey ended on 16 February 2020, immediately after the report of the first death from the COVID-19 virus in Taiwan.

If your IRB has waived written (signed) consent,

\section{Procedures}

The snowballing sampling technique was used to recruit the participants. The researchers used social networks, namely Facebook and LINE (the most popular messaging app in Taiwan) to circulate the survey link to all members of their contact lists. When participants anonymously completed the survey, they were encourage to disseminate the survey link to all their contacts with a thank note at the end. The participants were informed that their participation was voluntary, and consent was implied through their completion of the questionnaire. The questionnaire was developed in English and was then translated into Mandarin. Local experts validated the content of the questionnaire, after which it was pilot tested. The survey consisted of three sections, which assessed 1) demographic background, 2) anxiety symptoms, and 3) preventive measures.

\section{Anxiety symptoms}

The 6-item state version of the State-Trait Anxiety Inventory (STAI-6) assessing anxiety symptoms that was used in this study was adapted from previous studies $[17,18]$. The participants rated the frequency of experiencing six emotional states, namely being calm, tense, upset, relaxed, content, and worried, in relation to the current COVID-19 outbreak. A 4-point scale was used ( $1=$ not at all, $2=$ somewhat, $3=$ moderately, 4 = very much). The scores on the three positively-worded items were reverse coded. The participants were asked to rate each of the anxiety symptoms during the past week (PW) and during the beginning of the outbreak (BO). The anxiety symptoms during the PW are defined as the anxiety level between 8 February and the time of the survey. The anxiety level during the BO is defined as the anxiety symptoms experienced from the date of the Wuhan lockdown (23 January 2020) until 8 February 2020. The total summed scores were prorated (multiplied by 20/6) in order to obtain scores that were comparable with those from the full 20-item STAl (giving a range from 20 to 80) [17]. A cut-off score of 44 was used to indicate moderate to severe symptoms $[10,19,20]$. 


\section{Preventive measures}

Questions assessing preventive measures was developed for this study (Appendix 1). Preventive measures were assessed using questions that asked the participants about their personal protection (four items), cough etiquette (four items), contact precautions (two items), voluntary quarantine (one item), and prompt reporting (one item). The response option was on a 4-point Likert scale, with the items scored as 0 (rarely), 1 (occasionally), 2 (often), or 3 (always). The participants were asked to answer each question about the preventive measures they had carried out during the PW and during the BO. As with the anxiety levels, the preventive measures during the PW are defined as preventive measures carried out between 8 February and the time of the survey, and preventive measures during the $\mathrm{BO}$ are the measures carried out from the date of the Wuhan lockdown (23 January 2020) until 8 February 2020. The total score for the preventive measures is obtained by summing across all the questions. The possible score ranges from 0 to 36 , with higher scores indicating more preventive measures.

\section{Ethical considerations}

This study protocol was approved by the Research Ethics Committee of the National Taiwan Normal University (no. 202002HS007).

\section{Statistical analyses}

The reliability of the anxiety symptoms and preventive measure scores was evaluated by assessing the internal consistency of the items representing the scores. The 12 items for preventive measures had a reliability (Cronbach's a) of 0.891 . Multivariable logistic regression was used to determine the factors influencing an increase in the preventive measures score from the beginning of the outbreak to the past week. Variables that were significant using a chi-square $\left(c^{2}\right)$ test were selected for multivariate logistic regression analysis and included in the model, using a simultaneous forced-entry method. Odds ratios (OR), $95 \%$ confidence intervals $(95 \% \mathrm{Cl})$, and $p$ values were calculated for each independent variable. The model fit was assessed using the Hosmer-Lemeshow goodness-of-fit test [21]. All statistical analyses were performed using the Statistical Package for the Social Sciences, version 20.0 (IBM Corp., Armonk, NY, USA). A $p<$ value of less than 0.05 was considered statistically significant.

\section{Results}

Of a total of 3,555 complete responses, the majority were from the North district of Taiwan (66.3\%), were from females (78.2\%), and were from respondents aged $31-40$ years $(36.9 \%)$ or $41-50$ years $(28.4 \%)$. A summary of the characteristics of the respondents is provided in the first and second columns of Table 1.

\section{Anxiety symptoms}

Using a cut-off score of 44 for the STAI score, a total of $52.1 \%(95 \% \mathrm{Cl} 50.4-53.7)$ of the respondents reported moderate to severe levels of anxiety symptoms in the PW, whereas $48.8 \%(95 \% \mathrm{Cl} 47.2-50.5)$ 
reported moderate to severe levels of anxiety symptoms in the (BO) (Table 1). The highest proportions of moderate to severe cases of anxiety in the PW were observed in the $31-40$ years age group $(57.1 \% ; 95 \% \mathrm{Cl}$ $54.4-59.8)$, among women $(55.2 \% ; 95 \% \mathrm{Cl} 53.4-57.1)$, among those with an education level of high school and below $(56.0 \% ; 95 \% \mathrm{Cl} 49.6-62.2)$, and among respondents from the North district $(53.1 \%$; $95 \% \mathrm{Cl} 51.1-55.1)$. Respondents with an average household income of below NT\$20,000 (54.4\%; $95 \% \mathrm{Cl}$ $50.1-58.6)$ and those with an average household income between NT\$20,000 and NT\$50,000 (54.4\%; $95 \% \mathrm{Cl} 51.8-56.9)$ showed a similar proportion of moderate to severe cases of anxiety in the PW.

The highest proportion of moderate to severe cases of anxiety during the $\mathrm{BO}$ were observed in those aged $31-40$ years $(53.7 \%$; $95 \% \mathrm{Cl} 51.0-56.4)$, females $(51.9 \%$; $95 \% \mathrm{Cl} 50.0-53.7)$, those with a college education level $(51.2 \% ; 95 \% \mathrm{Cl} 49.1-53.4)$, and respondents with a household income between NT\$20,000 and NT\$50,000 (51.6\%; 95\%Cl 49.0-54.2). Among respondents from the North $(49.4 \% ; 95 \% \mathrm{Cl} 47.3-51.4)$ and Central $(49.7 \% ; 95 \% \mathrm{Cl} 45.8-53.7)$ districts there was a very similar proportion of moderate to severe cases of anxiety during the BO. On the whole, those in the older age group, males, those whose highest educational level was a degree and above, those in the higher income group and those in the South and East districts reported a lower level of anxiety symptoms during both the PW and the BO.

A comparison of the proportion of moderate to severe cases of anxiety during the PW and the BO revealed that significantly the highest increase in the proportion of moderate to severe cases of anxiety was among those in the $41-50$ years age group $(5.2 \% ; 95 \% \mathrm{Cl} 4.0-6.7)$. In contrast, among the respondents in the 20-30 year age group there was a decrease in the proportion with moderate to severe anxiety $(-2.8 \% ; 95 \% \mathrm{Cl}-9.2-3.6)$. The group of female participants showed a significantly higher increase in the proportion of moderate to severe cases of anxiety $(3.3 \% ; 95 \% \mathrm{Cl} 2.7-4.1)$ than the group of male participants $(2.7 \% ; 95 \% \mathrm{Cl} 1.8-4.1)$. The respondents whose highest educational level was high school or below $(6.0 \% ; 95 \% \mathrm{Cl} 3.7-9.7)$ and those in the income group below NT\$20,000 $(5.7 \% ; 95 \% \mathrm{Cl} 4.0-8.0)$ showed the highest increase in the proportion of those with moderate to severe anxiety. Respondents from the North $(3.7 \% ; 95 \% \mathrm{Cl} 3.0-4.6)$ and Central $(3.2 \% ; 95 \% \mathrm{Cl} 2.0-4.9)$ districts reported a higher increase in the proportion of those with moderate to severe anxiety than those from other districts.

The difference in the mean STAI score for the PW $(46.2, \mathrm{SD}=11.68)$ and the BO (45.0, SD=12.13) was statistically significant (Wilcoxon signed rank test $=6.414, p<0.001$ ). The median scores for anxiety symptoms during the PW and the BO were 46.7 (IQR 36.7-53.3) and 43.3 (IQR 36.7-53.3), respectively. The scale for both scores ranges from 20 to 80 . In total, $1,229(34.6 \% ; 95 \% \mathrm{Cl} 33.0-36.2)$ of the respondents recorded an increase in their anxiety score during the PW compared with the BO (PW score > BO score), and 2,326 (65.4\%; 95\% $\mathrm{Cl} 63.9-67.0)$ recorded a similar or lower anxiety score (PW score $\leq \mathrm{BO}$ score).

\section{Preventive measures}

The summary of responses in relation to preventive measures during the PW and BO is shown in Table 2 . Among the personal protection measures carried out during the $\mathrm{PW}$, the highest proportion was for respondents who frequently washed their hands with soap $(49.0 \%$; $95 \% \mathrm{Cl} 47.3-50.7)$, followed by those 
who wore a mask $(31.8 \% ; 95 \% \mathrm{Cl} 30.3-33.4)$. Under cough etiquette, the most commonly practised preventive measure was disposing of tissues immediately after coughing or sneezing $(80.1 \% ; 95 \% \mathrm{Cl}$ 78.9-81.4), and covering one's mouth and nose when coughing or sneezing $(65.2 \% ; 95 \% \mathrm{Cl} 63.6-66.7)$. Performing hand hygiene was reported always practised by a considerable proportion of the participants (60.3\%; 95\% Cl 58.6-61.9). Over a third of respondents reported that they always avoided proximity with others $(34.4 \% ; 95 \% \mathrm{Cl} 32.8-36.0)$ and avoided gathering in groups $(41.2 \% ; 95 \% \mathrm{Cl} 39.5-42.8)$. Near two thirds reported that they would always voluntarily quarantine themselves if they were feeling unwell $(61.6 \% ; 95 \% \mathrm{Cl} 60.0-63.2)$, but fewer than half said they would always report promptly to the health authorities if they were feeling unwell $(45.4 \% ; 95 \% \mathrm{Cl} 43.8-47.1)$.

Similar findings were reported for preventive measures at the BO, with the highest proportion reporting that they had always disposed of tissues immediately after coughing and sneezing $(66.5 \%$; $95 \% \mathrm{Cl} 64.9-$ $68.0)$, followed by those who had covered their mouths and noses when coughing or sneezing $(62.2 \%$; $95 \% \mathrm{Cl} 60.6-63.8)$. The proportion who practised contact precautions was relatively low. A comparison of the proportions who always practised particular preventive measures during the PW and the BO shows that disposing of tissues immediately after coughing and sneezing recorded the highest increase $(13.6 \%$; $95 \% \mathrm{Cl} 12.6-14.8)$, followed by avoiding group gatherings $(10.3 \% ; 95 \% \mathrm{Cl} 9.4-11.4)$ and frequently washing hands $(10.8 \% ; 95 \% \mathrm{Cl} 9.8-11.8)$. A lower increment in the proportion can be seen for using eye protection $(1.9 \% ; 95 \% \mathrm{Cl} 1.5-2.4)$ and covering one's mouth and nose when coughing or sneezing $(3.0 \%$; $95 \% \mathrm{Cl} 2.4-3.6)$.

The difference in the mean total scores for preventive measures during the PW $(25.4, S D=5.85)$ and the BO $(23.4, S D=6.56)$ was statistically significant (Wilcoxon signed rank test $=23.917, p<0.001)$. The median scores for preventive measures during the PW and the BO were 26.0 (IQR 21.0-30.0) and 24.0 (IQR 19.0-28.0), respectively. The total score for preventive measures during the PW ranges from 2 to 36 , whereas the total score for preventive measures during the BO ranges from 0 to 36 . For the respondents overall, a total of $1,696(47.7 \%, 95 \% \mathrm{Cl}: 46.1-49.4)$ reported an increase in their total preventive measures score during the PW compared with their score during the BO and 1,859 (52.3\%, 95\% Cl: 50.6-53.9) reported similar or lower total preventive measures scores.

Table 3 shows the univariate and multivariable analyses of the factors associated with a higher total preventive measures score when comparing the PW with the BO. Having an increased anxiety score during the $\mathrm{PW}$ compare with the score during the $\mathrm{BO}$ (adjusted $\mathrm{OR}=7.38,95 \% \mathrm{Cl} 6.28-8.66$ ) was a strongly significant determinant of an increase in the preventive measure score from the BO to the PW. Respondents with a college level of education (adjusted OR $=1.58,95 \% 1.17-2.13$ ) or graduate level and above (adjusted OR $=1.74,95 \%$ 1.28-2.38) were more likely to have an increased preventive measure score from the $\mathrm{BO}$ to the PW compared to those whose highest education level was high school and below.

\section{Discussion}


Approximately three weeks after the widespread news of the lockdown of the epicentre of COVID-19, this study found the alarming result that over half $(52.1 \%)$ of Taiwanese lay members of the public who participated in the survey had moderate to severe levels of anxiety. Those in the younger age groups, females, and those with a lower educational background and in lower income groups were found to show more anxiety symptoms, and this provides valuable information to allow public health authorities and stakeholders to coordinate their targeted mental health interventions. Despite it being widely circulated in the news media that it is likely that older adults affected by COVID-19 have a higher risk of complications and mortality, and the recent large report on epidemiological data from the Chinese Centre for Disease Control and Prevention that showed that those aged above 60 years accounted for $44.1 \%$ of confirmed cases in Wuhan [22], the study participants in the older age group appear to have a lower level of anxiety. Further studies are warranted to elucidate whether the low anxiety stems from a lack of knowledge or to their being out-of-touch with current media interventions. The exponential increase in confirmed COVID-19 cases in mainland China following the lockdown, as well as increasing numbers of cases outside China, including in Taiwan, has sparked global concern and likewise an increase in the anxiety levels among the participants in this study. Concurrent with the relatively low level of anxiety among those with higher education and higher income, the increase in anxiety levels was also lowest among the group with higher socio-economic status. The underlying reasons for the socio-economic disparities in anxiety also warrant further investigation in the future.

Our study participants were taking relatively good preventive measures, evidenced by the median scores of 25 and 23, out of a possible score of 36 , for the past week and the beginning of the outbreak, respectively. Further, nearly half of them reported improved prevention practices in the past week compared to the beginning of the outbreak. The study also found a considerable increase in preventive measures related to hand washing, cough etiquette, and contact precaution, which perhaps explains why, to date, only 20 confirmed cases have been reported in Taiwan, despite it being in close geographical proximity to mainland China and having a high volume of travellers to and from mainland China prior to the outbreak. Nonetheless, the findings highlight the need to improve contact precautions, since the proportion of respondents who were avoiding proximity and group gatherings remained low at both the beginning of outbreak and in the past week. Multivariable analyses revealed that participants with higher education levels reported a higher increase in their preventive measures. A higher increase in anxiety symptoms was also associated with a greater increase in preventive practices. This finding is in congruence with previous findings from the SARS outbreak in Hong Kong where a positive dose-response gradient between anxiety level and uptake of personal protective measures was found [15], which suggests that the right amount of anxiety, so long as it is not at the level that could result in a detrimental health impact, can perhaps help to stimulate practices that prevent an epidemic.

The current study has several limitations. The first limitation is that the responses were based on selfreporting and may be subject to self-report and recall bias. Second, the snowballing method used in this study can lead to selection bias. It is notable that the study has an over-representation of female participants and an unequal distribution of respondents between the districts of Taiwan. Nevertheless, during the period of crisis for the outbreak, the snowballing method, which used LINE and Facebook, the 
largest social media platform in Taiwan, was extremely effective in achieving a broad coverage of participants. Despite these limitations, the study contributes tremendously to the understanding of the psychological well-being and psychobehavioural responses of the general public in Taiwan associated with COVID-19 while the epidemic is still on-going.

\section{Conclusion}

The study revealed the need to reduce public anxiety levels and to maintain appropriate infection prevention against COVID-19. It is of the utmost urgency that public health interventions are carried out to reach the identified groups of people with poor adherence to preventive measures. Considering the extremely contagious nature of COVID-19, a slight lack of compliance by even a small portion of the population may have grave consequences and contribute to the continued spread of the outbreak. The prominent psychological effects and psychobehavioural responses to the outbreak found in this study provide important information for developing and implementing effective preventive and emotional regulation control strategies.

\section{Abbreviations}

BO: Beginning outbreak

Cl: Confidence Interval

COVID-19: Coronavirus disease-2019

H1N1: influenza A

NT\$: New Taiwan Dollar

PW: Past week

SARS: Severe acute respiratory syndrome

STAI-6: State-Trait Anxiety Inventory

WHO: World Health Organization

\section{Declarations}

\section{Ethics approval and consent to participate}

This study protocol was approved by the Research Ethics Committee of the National Taiwan Normal University (no. 202002HS007). 
Not applicable

\section{Availability of data and materials}

The datasets used and analyzed during the current study are available from the corresponding author on reasonable request.

\section{Competing interest}

The authors declare that they have no competing interests

\section{Author Contributions}

LPW and TSHL conceived the study. CCH and TSHL conducted and collected data. LPW and HA analysed the data. LPW wrote the manuscript. All authors have approved the manuscript.

\section{Funding}

This study was supported by the National Taiwan Normal University. The research team is independent of the funding agencies and the funding agencies were not involved in the design, interpretation or writing of the manuscript.

\section{Acknowledgments}

The study would like to thank all participants involved in this study.

\section{References}

1. Lu R, Zhao X, Li J, Niu P, Yang B, Wu H, Wang W, Song H, Huang B, Zhu N, Bi Y. Genomic characterisation and epidemiology of 2019 novel coronavirus: implications for virus origins and receptor binding. The Lancet. 2020;395:565-574.https://doi.org/10.1016/S0140-6736(20)30251-8.

2. WHO. Coronavirus disease (COVID-19) outbreak. 2020. https://www.who.int/emergencies/diseases/novel-coronavirus-2019. Accessed 20 February 2020.

3. WHO. Coronavirus disease 2019 (COVID-19). Situation report-29. 2020. https://www.who.int/docs/default-source/coronaviruse/situation-reports/20200218-sitrep-29-covid19.pdf. Accessed 20 February 2020.

4. CDC. Coronavirus Disease 2019 (COVID-19). Information for Travel. 2020. https://www.cdc.gov/coronavirus/2019-ncov/travelers/index.html .Accessed 21 February 2020.

5. Bao Y, Sun Y, Meng S, Shi J, Lu L. 2019-nCoV epidemic: address mental health care to empower society. The Lancet. 2020. Published online 7 Feb 2020.

6. Cowling BJ, Ng DM, Ip DK, Liao Q, Lam WW, Wu JT, Lau JT, Griffiths SM, Fielding R. Community psychological and behavioral responses through the first wave of the 2009 influenza A (H1N1) 
pandemic in Hong Kong. The Journal of Infectious Diseases. 2010;202:867-76.

https://doi.org/10.1086/655811.

7. Jalloh MF, Li W, Bunnell RE, Ethier KA, O'Leary A, Hageman KM, Sengeh P, Jalloh MB, Morgan O, Hersey S, Marston BJ. Impact of Ebola experiences and risk perceptions on mental health in Sierra Leone, July 2015. BMJ Global Health. 2018;3:e000471.doi: 10.1136/bmjgh-2017-000471;

8. Rubin GJ, Amlôt R, Page L, Wessely S. Public perceptions, anxiety, and behaviour change in relation to the swine flu outbreak: cross sectional telephone survey. BMJ.2009;339:b2651. doi: https://doi.org/10.1136/bmj.b2651

9. Vijaya K, Low YY, Chan SP, Foo LL, Lee M, Deurenberg-Yap M. Behaviour of Singaporeans during the SARS outbreak: The impact of anxiety and public satisfaction with media information. International Journal Health Promotion and Education. 2005;43:17-22.

https://doi.org/10.1080/14635240.2005.10708030

10. Leung GM, Ho LM, Chan SK, Ho SY, Bacon-Shone J, Choy RY, Hedley AJ, Lam TH, Fielding R. Longitudinal assessment of community psychobehavioral responses during and after the 2003 outbreak of severe acute respiratory syndrome in Hong Kong. Clinical Infectious Diseases. 2015; 40:1713-20. DOI:10.1086/429923

11. Taylor MR, Agho KE, Stevens GJ, Raphael B. Factors influencing psychological distress during a disease epidemic: data from Australia's first outbreak of equine influenza. BMC Public Health. 2008;8:347. https://doi.org/10.1186/1471-2458-8-347

12. Marshall GD. The adverse effects of psychological stress on immunoregulatory balance: applications to human inflammatory diseases. Immunology and Allergy Clinics. 2011; 31:133-40. doi: 10.1016/j.iac.2010.09.013

13. Segerstrom SC, Miller GE. Psychological stress and the human immune system: a meta-analytic study of 30 years of inquiry. Psychological Bulletin. 2004;130:601. doi: 10.1037/00332909.130.4.601

14. Chen N, Zhou M, Dong X, Qu J, Gong F, Han Y, Qiu Y, Wang J, Liu Y, Wei Y, Yu T. Epidemiological and clinical characteristics of 99 cases of 2019 novel coronavirus pneumonia in Wuhan, China: a descriptive study. The Lancet. 2020;395:507-513.DOI: https://doi.org/10.1016/S01406736(20)30211-7.

15. Lau JT, Yang X, Tsui H, Kim JH. Monitoring community responses to the SARS epidemic in Hong Kong: from day 10 to day 62. Journal of Epidemiology \& Community Health. 2003; 57:864-70. http://dx.doi.org/10.1136/jech.57.11.864

16. Leung GM, Quah S, Ho LM, Ho SY, Hedley AJ, Lee HP, Lam TH. A tale of two cities: community psychobehavioral surveillance and related impact on outbreak control in Hong Kong and Singapore during the severe acute respiratory syndrome epidemic. Infection Control \& Hospital Epidemiology. 2004;25:1033-41. DOI: 10.1086/502340

17. Hou WK, Hall BJ, Canetti D, Lau KM, Ng SM, Hobfoll SE. Threat to democracy: Physical and mental health impact of democracy movement in Hong Kong. Journal of Affective Disorders. 2015;186:74- 
82. doi: 10.1016/j.jad.2015.07.005

18. Marteau TM, Bekker $\mathrm{H}$. The development of a six-item short-form of the state scale of the Spielberger State-Trait Anxiety Inventory (STAI). British journal of clinical Psychology. 1992;31:301-6. https://doi.org/10.1111/j.2044-8260.1992.tb00997.x

19. Knight RG, Waal-Manning HJ, Spears GF. Some norms and reliability data for the State-Trait Anxiety Inventory and the Zung Self-Rating Depression scale. British Journal of Clinical Psychology. 1983;22:245-9. http://dx.doi.org/10.1111/j.2044-8260.1983.tb00610.x.

20. Speilberger CD, Gorsuch RL, Lushene R, Vagg R, Jacobs GS. Manual for the Stait-Trait Anxiety Inventory. CA:Consulting Psychologists Press; 1983

21. Hosmer Jr DW, Lemeshow S, Sturdivant R. Applied logistic regression. John Wiley \& Son; 2013

22. Novel CP. The epidemiological characteristics of an outbreak of 2019 novel coronavirus diseases (COVID-19) in China. Zhonghua liu xing bing xue za zhi= Zhonghua liuxingbingxue zazhi. 2020;41:145. doi: 10.3760/cma.j.issn.0254-6450.2020.02.003

\section{Tables}

Table 1 Participant characteristics and anxiety symptom score past week and beginning of the outbreak $(\mathrm{N}=3555)$ 


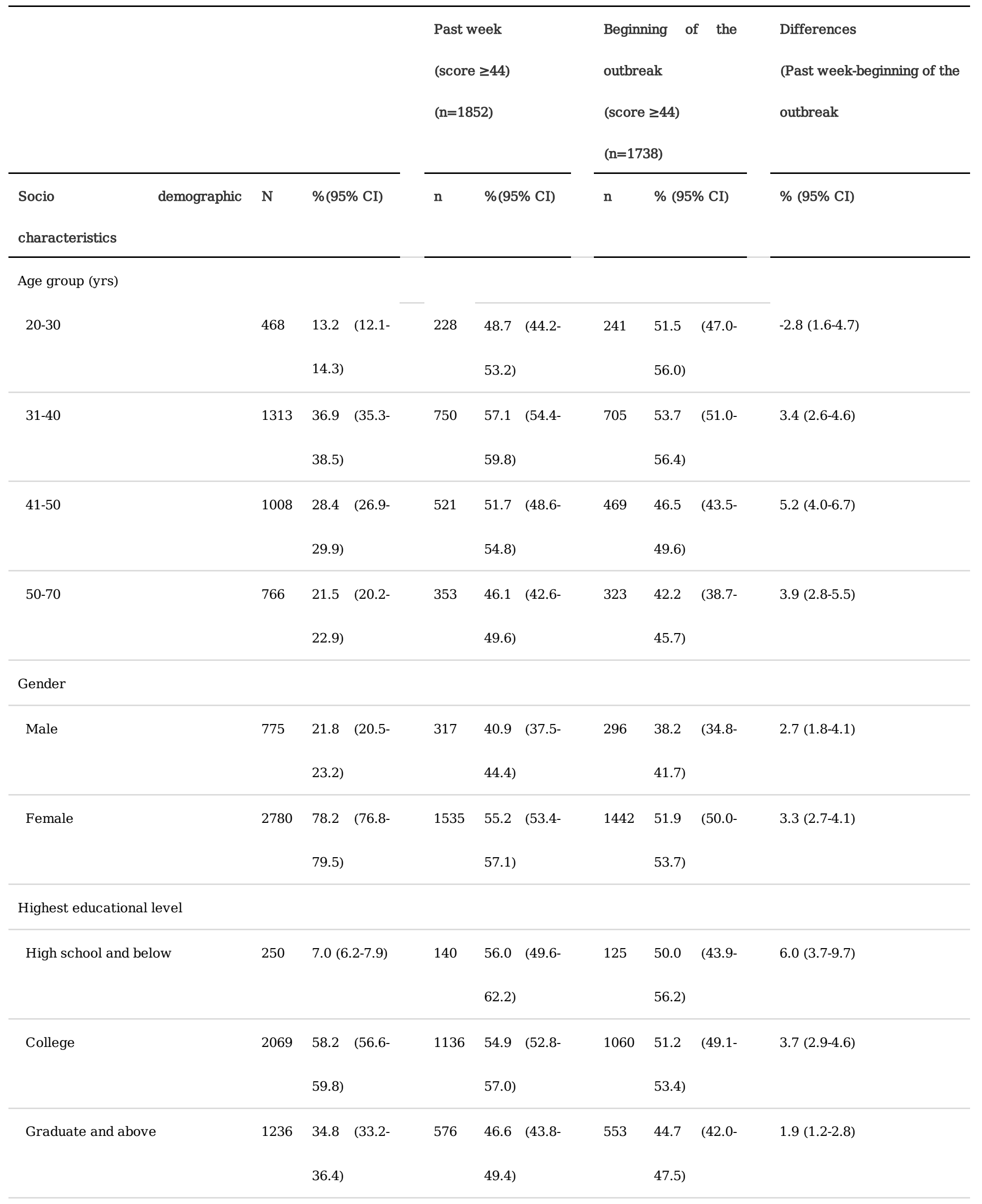

Average monthly household 


\begin{tabular}{|c|c|c|c|c|c|c|c|c|c|c|}
\hline$<20,000$ & 528 & 14.9 & $(13.7-$ & 287 & 54.4 & $(50.1-$ & 257 & 48.7 & $(44.4-$ & $5.7(4.0-8.0)$ \\
\hline & & 16.1) & & & 58.6) & & & 52.9) & & \\
\hline \multirow[t]{2}{*}{$20,000-50,000$} & 1440 & 40.5 & (38.9- & 783 & 54.4 & $(51.8-$ & 743 & 51.6 & $(49.0-$ & $2.8(2.1-3.8)$ \\
\hline & & 42.1) & & & 56.9) & & & $54.2)$ & & \\
\hline \multirow[t]{2}{*}{$50,000-100,000$} & 1251 & 35.2 & (33.6- & 647 & 51.7 & $(49.0-$ & 608 & 48.6 & $(45.8-$ & $3.1(2.3-4.2)$ \\
\hline & & $36.8)$ & & & 54.5) & & & 51.4) & & \\
\hline \multirow[t]{2}{*}{$>100,000$} & 336 & 9.5 & $(8.5-$ & 135 & 40.2 & (35.1- & 130 & 38.7 & (33.6- & $1.5(0.6-3.4)$ \\
\hline & & 10.5) & & & 45.5) & & & $44.0)$ & & \\
\hline \multicolumn{11}{|l|}{ Location } \\
\hline \multirow[t]{2}{*}{ North district } & 2358 & 66.3 & (64.7- & 1252 & 53.1 & (51.1- & 1164 & 49.4 & (47.3- & $3.7(3.0-4.6)$ \\
\hline & & 67.9) & & & $55.1)$ & & & 51.4) & & \\
\hline \multirow[t]{2}{*}{ Central district } & 599 & 16.8 & $(15.6-$ & 317 & 52.9 & $(48.9-$ & 298 & 49.7 & $(45.8-$ & $3.2(2.0-4.9)$ \\
\hline & & 18.1) & & & 56.9) & & & $53.7)$ & & \\
\hline \multirow[t]{2}{*}{ South district } & 484 & 13.6 & $(12.5-$ & 239 & 49.4 & $(45.0-$ & 233 & 48.1 & (43.7- & $1.3(0.6-2.7)$ \\
\hline & & 14.8) & & & 53.8) & & & 52.6) & & \\
\hline
\end{tabular}

Table 2 Differences in prevention measures the past week and beginning of the outbreak $(\mathrm{N}=3555)$ 


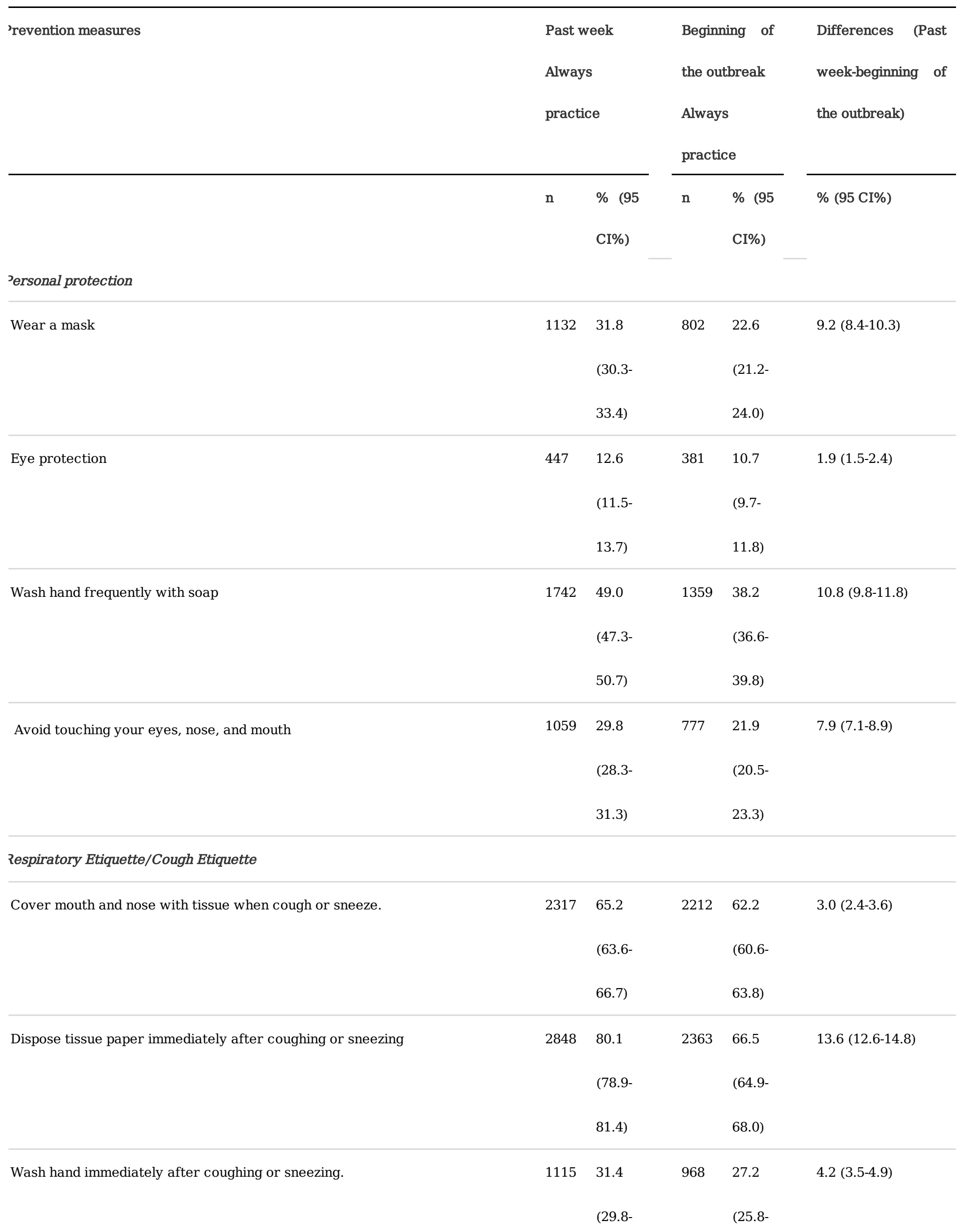




\begin{tabular}{|c|c|c|c|c|c|}
\hline & & 32.9) & & 28.7) & \\
\hline Perform hand hygiene (e.g., hand washing with or antiseptic handwash) after & 2142 & 60.3 & 1904 & 53.6 & $6.7(5.9-7.6)$ \\
\hline \multirow[t]{2}{*}{ laving contact with respiratory secretions or contaminated objects } & & $(58.6-$ & & $(51.9-$ & \\
\hline & & 61.9) & & $55.2)$ & \\
\hline \multicolumn{6}{|l|}{ Zontact precautious } \\
\hline \multirow[t]{3}{*}{ Avoid proximity (closeness) with other people } & 1222 & 34.4 & 961 & 27.0 & $7.3(6.5-8.2)$ \\
\hline & & $(32.8-$ & & $(25.6-$ & \\
\hline & & $36.0)$ & & 28.5) & \\
\hline \multirow[t]{3}{*}{ Avoid group gathering } & 1463 & 41.2 & 1096 & 30.8 & $10.3(9.4-11.4)$ \\
\hline & & $(39.5-$ & & $(29.3-$ & \\
\hline & & 42.8) & & 32.4) & \\
\hline
\end{tabular}

\section{Toluntary quarantine}

If I am feeling unwell, I distance myself from others

\begin{tabular}{|c|c|c|c|c|}
\hline 2191 & 61.6 & 2016 & 56.7 & $4.9(4.3-5.7)$ \\
\hline & (60.0- & & (55.1- & \\
\hline & 63.2) & & 58.3) & \\
\hline
\end{tabular}

\section{'rompt reporting}

If I am feeling unwell, I will immediately declare my symptoms to the 161545.4 uthority/healthcare providers
$(43.8-$

47.1)
$1410 \quad 39.7$

(38.0-

41.3)

Table 3 Factors associated with differences in total preventive measure scores $(\mathrm{N}=3555)$ 


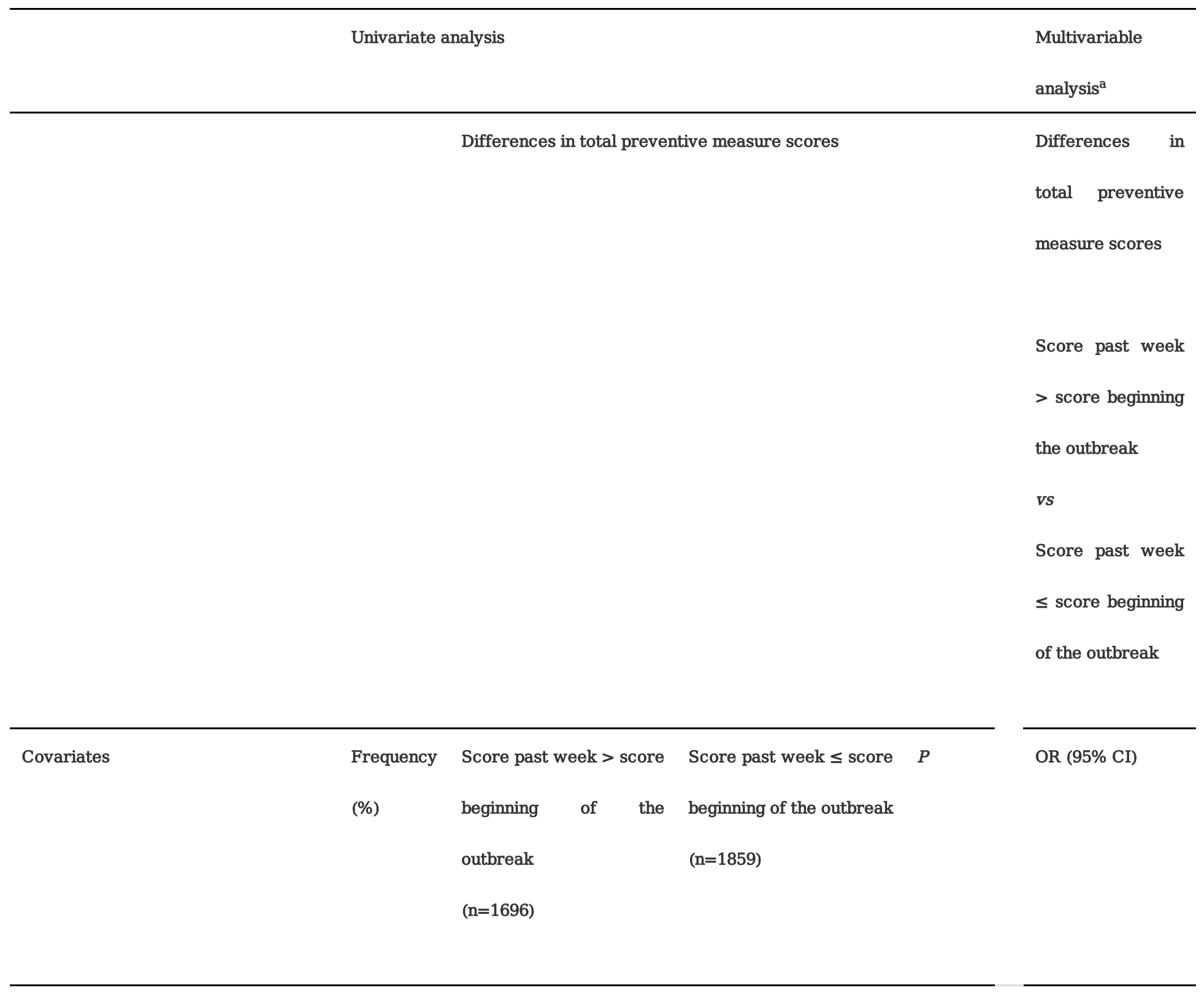

Socio demographic characteristics

Age group (yrs)

\begin{tabular}{|c|c|c|c|c|}
\hline $20-30$ & 468 (13.2) & 227 (48.5) & 241 (51.5) & \\
\hline \multirow[t]{2}{*}{$31-40$} & 1313 & $638(48.6)$ & $675(51.4)$ & 0.735 \\
\hline & (36.9) & & & \\
\hline \multirow[t]{2}{*}{$41-50$} & 1008 & $477(47.3)$ & $531(52.7)$ & \\
\hline & $(28.4)$ & & & \\
\hline $50-70$ & 766 (21.5) & $354(46.2)$ & $412(53.8)$ & \\
\hline \multicolumn{5}{|l|}{ Gender } \\
\hline Male & $775(21.8)$ & $372(48.0)$ & $403(52.0)$ & 0.871 \\
\hline
\end{tabular}


(78.2)

Highest educational level

\begin{tabular}{|c|c|c|c|c|c|}
\hline High school and below & $250(7.0)$ & $96(38.4)$ & $154(61.6)$ & & Ref \\
\hline \multirow[t]{2}{*}{ College } & 2069 & $994(48.0)$ & $1075(52.0)$ & 0.008 & $1.58(1.17-2.13)^{* *}$ \\
\hline & $(58.2)$ & & & & \\
\hline \multirow[t]{2}{*}{ Graduate and above } & 1236 & $606(49.0)$ & $630(51.0)$ & & $1.74(1.28-2.38)^{* * *}$ \\
\hline & $(34.8)$ & & & & \\
\hline Average monthly household income & & & & & Ref \\
\hline \multicolumn{6}{|l|}{$(\mathrm{NT} \$)$} \\
\hline$<20,000$ & $528(14.9)$ & $232(43.9)$ & $296(56.1)$ & & \\
\hline \multirow[t]{2}{*}{$20,000-50,000$} & 1440 & $688(47.8)$ & $752(52.2)$ & 0.138 & \\
\hline & $(40.5)$ & & & & \\
\hline \multirow[t]{2}{*}{$50,000-100,000$} & 1251 & $622(49.7)$ & $629(50.3)$ & & \\
\hline & $(35.2)$ & & & & \\
\hline$>100,000$ & $336(9.5)$ & $154(45.8)$ & $182(54.2)$ & & \\
\hline \multicolumn{6}{|l|}{ Location } \\
\hline \multirow[t]{2}{*}{ North district } & 2358 & $1128(47.8)$ & $1230(52.2)$ & & \\
\hline & $(66.3)$ & & & & \\
\hline Central district & $599(16.8)$ & $277(46.2)$ & $322(53.8)$ & 0.838 & \\
\hline South district & $484(13.6)$ & $234(48.3)$ & $250(51.7)$ & & \\
\hline East district & $114(3.2)$ & $57(50.0)$ & $57(50.0)$ & & \\
\hline
\end{tabular}

\section{Anxiety symptom score}

Differences in score between past

one week and beginning the outbreak

$\begin{array}{lllll}\text { Score past one week } \leq \text { score } 2326 & 744(32.0) & 1582(68.0) & \text { pef } \\ \text { beginning the outbreak } & (65.4) & & \end{array}$


$* * \mathrm{p}<0.01, * * * \mathrm{p}<0.001$

${ }^{a}$ Hosmer-Lemeshow test, chi-square: 4.812, p-value: 0.307 ; Nagelkerke $\mathrm{R}^{2}: 0.240$

\section{Supplementary Files}

This is a list of supplementary files associated with this preprint. Click to download.

- Appendix1.docx 